\title{
Performance Assurance of Hydraulic Shock-Absorbers at Subzero Temperatures
}

\author{
Dmitriy Domnyshev, Aleksey Dolgushin, Dmitriy Voronin, Yuriy Blynskiy and Anton Kurnosov \\ Federal State Budgetary Educational Establishment of Higher Education, \\ Novosibirsk State Agrarian University, Dobroluybov St., 160, Novosibirsk, Russia \\ demon-doom1990@yandex.ru
}

\begin{abstract}
The use of production vehicles often takes place at extreme low temperatures which leads to increase in operational costs. Thermal abuse of main units and nodes is caused primarily by the change in viscosity-temperature properties of power fluids. Performance of a suspension hydraulic shock-absorber is tightly connected with viscosity properties of the power fluid. One of the basic criteria of hydraulic shock-absorber performance at subzero temperatures is resistance force. Based on the performed studies, resistance forces of hydraulic shock-absorbers in temperature range from $30^{\circ} \mathrm{C}$ below zero to $10^{\circ} \mathrm{C}$ below zero change from $3230-4500 \mathrm{~N}$ at rebound with the max allowable value of $4022 \mathrm{~N}$ and from $830-1410 \mathrm{~N}$ at compression with the max allowable value of $1226 \mathrm{~N}$. The above figures indicate performance deterioration. In this research, we suggest assuring performance of hydraulic shock-absorbers by using a modified shock-absorber fluid. Adding $25 \%$ of diesel fuel by total volume helped to decrease dynamic viscosity of the shock-absorber fluid two times compared to a standard fluid at a given temperature. The use of the designed test fluid will help to increase performance of the suspension and ensure the performance of hydraulic shock-absorbers at subzero temperatures.
\end{abstract}

Key words: Hydraulic shock-absorbers, suspension, modified test shock-absorber fluid, performance of hydraulic shock-absorbers, resistance force, compression

\section{INTRODUCTION}

Assurance of operational conditions and reliability of vehicle engineering systems in various natural climatic conditions is the priority of ETS of enterprises that use these vehicles. It is known that the agricultural sector mostly uses automobile transport to transfer goods (Ryabov et al., 2014). Vehicles, used on public-access roads, must be in good working order and repair regardless of ambient temperature. This is the most critical safety demand for passenger and cargo transportation.

Production vehicles are used in a wide temperature range. Thus, in Russia, Canada, Swede, Norway and some other countries vehicles are used at subzero temperatures during most part of the year. Modern vehicles are not quite fitted to be used in such conditions for a long time and that significantly affects performance and capacity of the majority of vehicle's units (Gardulski and Warczek, 2008; Burdzik and Konieczny, 2008; Konieczny et al., 2009).

When used in such conditions, performance and resource consumption of some units and nodes deteriorate. Among most vulnerable nodes are suspension hydraulic shock-absorbers.
Efficiency of the suspension is conditioned by the performance of hydraulic absorbers (Izmaylov and Yevtyushenko, 2013). According to Anonymous (2012) the performance index of hydraulic shock-absorbers is based on resistance force maximum values at compression and rebound, all values above maximum or decrease in resistance by more than $15 \%$ indicates that a shockabsorber is non operable. Poor performance of hydraulic chock-absorbers negatively affects driving comfort, public road safety, cargo safety conditions, average transportation speed, operating and trouble-free life of main components and units of vehicles (Domnyshev et al., 2016). Performance of hydraulic shock-absorbers also affects stability of the tyre-tread and road contact as absorption of vibrations the undercarriage gets from the road determines stability and behaviour of a vehicle as well as its breaking path under emergency braking conditions (Sobczak, 2009; Gardulski, 2009). Thus, shock absorbers are the crucial element of the vehicle safety.

According to TUV tests, non operable hydraulic shock-absorbers increase vehicle's breaking path by $28.3 \%$. If shock-absorbers are non operable, a vehicle loses road grip when encountering minor road irregularities which cause resonance vibration of wheels

Corresponding Author: Dmitriy Domnyshev, Federal State Budgetary Educational Establishment of Higher Education, Novosibirsk State Agrarian University, Dobroluybov St., 160, Novosibirsk, Russia, demon-doom 1990@yandex.ru 
(vehicle's unsprung weight). Maximum safe speed of such vehicle must not exceed $57 \mathrm{~km} / \mathrm{h}$ (Ryabov et al., 2014; Karasev, 2011). As indicated in studies, Ishchenko and Shcherbina (2017), Alekseevich et al. (2016) and Domnyshev et al. (2016), the majority of all suspension failures are connected with the malfunction of hydraulic shock-absorbers. We thoroughly studied shock-absorber failure causes and determined some major ones:

- Shock-absorber seal failure

- Scoring and wear-out of the rod bearing surface, rod geometry perturbation

- Failure of rebound and compression valves

- Wear-out or failure of a piston O-ring

Most of these failures are caused by an increase in viscosity of the power fluid and resistance forces during rod shifting inside the shock-absorber. Performed studies (Domnyshev et al., 2016) prove that decrease in the shock-absorber fluid temperature increases resistance forces of moving parts of the shock-absorber due to increased viscosity of the shock-absorber fluid.

The main objective of this work is to design a method of performance assurance of shock-absorbers of truck vehicles, based on the use of a modified shock-absorber fluid.

\section{MATERIALS AND METHODS}

At the first stage, we performed a theoretical study of performance parameter variations in hydraulic shock-absorbers at subzero temperatures. At the second stage, we conducted a proof-of-model experiment in terms of its adequacy and estimated applicability of the modified shock-absorber fluid.

To conduct active experiments, we prepared a test assembly. As a test object, we chose to use shock-absorbers of a KAMAZ truck front suspension group. We also, set up a PC-based measuring equipment comprising temperature measurement devices to measure both shock-absorber fluid temperature and ambient temperature. According to planning of experiments, on the operational test stand, we studied how shock-absorber performance depends on the ambient temperature, speed and amount of rod movement (Domnyshev et al., 2016).

Studies were performed within the ambient temperature range from $30^{\circ} \mathrm{C}$ below zero to $10^{\circ} \mathrm{C}$ below zero at rod movement speed of $0.52 \mathrm{~m} / \mathrm{sec}$ and the amount of movement $0.05 \mathrm{~m}$ (Anonymous, 2012).
Resistance was measured using strain-gage instrumentation, values stored on PC. Shock-absorber fluid temperature readings were recorded by using gauges in inner tanks of hydraulic shock-absorbers. Dynamic viscosity of fluids in use was measured by a rotation viscometer. We used a standard shock-absorber fluid AZh-12T (AK-12T) and a special mix of a shock-absorber fluid and a diesel fluid.

To determine dependencies of viscosity-temperature properties of the shock-absorber fluid on resistance forces, we designed a mathematical apparatus based on standard formulae. Resistance forces at rebound and compression were determined by the following Eq. 1 and 2 :

$$
\begin{gathered}
\mathrm{F}_{\text {comp. }}=\frac{\left(\mathrm{k}_{\mathrm{y}} \cdot v_{\text {rod }}\right)^{2}}{\mu^{2}} \cdot \frac{\mathrm{S}_{\text {comp. } .} \cdot \rho}{2 \cdot \mathrm{S}_{\text {orif.(comp.) }}} \\
\mathrm{F}_{\text {reb. }}=\frac{\left(\mathrm{k}_{\mathrm{y}} \cdot v_{\mathrm{wm}}\right)^{2}}{\mu^{2}} \cdot \frac{\mathrm{S}_{\text {reb. } .} \cdot \rho}{2 \cdot \mathrm{S}_{\text {orif.(reb.) }}}
\end{gathered}
$$

Where:

$\mathrm{F}_{\text {com },}=$ Resistance Forces of a hydraulic shock-

$\mathrm{F}_{\text {reb. }} \quad$ absorber at rebound or compression $(\mathrm{N})$

$\mathrm{k}_{\mathrm{y}}=$ The coefficient of shock-absorber fluid leakage which characterizes the sealing capacity of the O-ring to cylinder walls when hydraulic shock-absorbers are operable

$v_{\text {rod }}=$ The movement speed of the shock-absorber $\operatorname{rod}(\mathrm{m} / \mathrm{sec})$

$\mu=$ The coefficient of shock-absorber fluid consumption which depends on the fluid compression coefficient and on how fast it passes through the valve hole

$\mathrm{S}_{\text {comp., }}=$ The piston area at compression and rebound

$\mathrm{S}_{\mathrm{reb}} \quad\left(\mathrm{mm}^{2}\right)$

$\rho=$ The shock-absorber fluid density at the temperature of $20^{\circ} \mathrm{C}\left(\mathrm{kg} / \mathrm{m}^{3}\right)$

$\mathrm{S}_{\text {orif(reb.), }}=$ The orifice area of the displacing piston at

$\mathrm{S}_{\text {orif.(comp.) }} \quad$ rebound and compression $\left(\mathrm{mm}^{2}\right)$

However, expressions (Eq. 1) and (2) use density of the shock-absorber fluid at the temperature $20^{\circ} \mathrm{C}$. To determine resistance forces in the given temperature range it is necessary to consider density-temperature relation. Functional relation between shock-absorber fluid and its temperature can be determined by the following Eq. 3:

$$
\rho=\rho_{20}[1+\zeta(20-T)]
$$

Where:

$\rho_{20}=$ Density of the shock-absorber fluid at the ambient temperature $20^{\circ} \mathrm{C}\left(\mathrm{kg} / \mathrm{m}^{3}\right)$ 
$\zeta=$ The coefficient of cubic expansion of oil-based process fluids $(1 / \mathrm{K})$

$\mathrm{T}=$ The shock-absorber fluid temperature $\left({ }^{\circ} \mathrm{C}\right)$

Plugging (Eq. 1-3), we will get equations to determine resistance forces at rebound and compression of shock-absorbers at subzero temperatures:

$$
\begin{aligned}
& \mathrm{F}_{\text {comp. }}=\frac{\left(\mathrm{k}_{\mathrm{y}} \cdot v_{\text {rod }}\right)^{2}}{\mu^{2}} \cdot \frac{\mathrm{S}_{\text {comp. }} \cdot\left(\rho_{20}[1+\zeta \cdot(20-\mathrm{T}]\right.}{2 \cdot \mathrm{S}_{\text {orif.(comp.) }}} \\
& \mathrm{F}_{\text {comp. }}=\frac{\left(\mathrm{k}_{\mathrm{y}} \cdot v_{\text {rod }}\right)^{2}}{\mu^{2}} \cdot \frac{\mathrm{S}_{\text {reb. } 3} \cdot\left(\rho_{20}[1+\zeta \cdot(20-\mathrm{T}]\right.}{2 \cdot \mathrm{S}_{\text {orif. (reb.) }}}
\end{aligned}
$$

\section{RESULTS AND DISCUSSION}

While we were studying performance of truck shock-absorbers in relation to the operating temperature, we determined that operation of shock-absorbers is attended by a minor increase in the shock-absorber fluid temperature. With certain assumptions, we can consider the shock-absorber fluid temperature equal to the ambient operating temperature.

After a detailed analysis of shock-absorber resistance changes at subzero temperatures (Fig. 1), we determined a performance temperature range of hydraulic shock-absorbers within which resistance forces at rebound $\mathrm{F}_{\text {rebound }}$ and compression $\mathrm{F}_{\text {compress }}$ exceed maximum factory values for given shock-absorbers. The high-limit temperature of the research is $27^{\circ} \mathrm{C}$ below zero. The shaded area of the chart illustrates an operational condition of hydraulic shock-absorbers. If resistance values remain in a critical range for a long time, it may lead to life shortening and failures.

This relation allows to estimate performance of hydraulic shock-absorbers in the given subzero temperature range. As resistance forces of shockabsorbers and viscosity-temperature properties of the power fluid are functionally related, it is possible to ensure performance of hydraulic shock-absorbers through managing viscosity of the shock-absorber fluid. Hydraulic shock-absorber's loss of function, mentioned above can be explained by the viscosity growth of the power fluid. To prevent this, we suggest using various means to improve viscosity-temperature properties of the fluid (Domnyshev et al., 2016; Brusyantsev et al., 1954). One of the ways to do it is to use diesel fuel (Domnyshev et al., 2016). As shown on Fig. 2, adding up to $25 \%$ of diesel fuel to the shock-absorber fluid leads to almost twofold decrease in viscosity of the test (2) shock-absorber fluid, compared to the fluid AZh12-T (1) used at temperature $30^{\circ} \mathrm{C}$ and below.

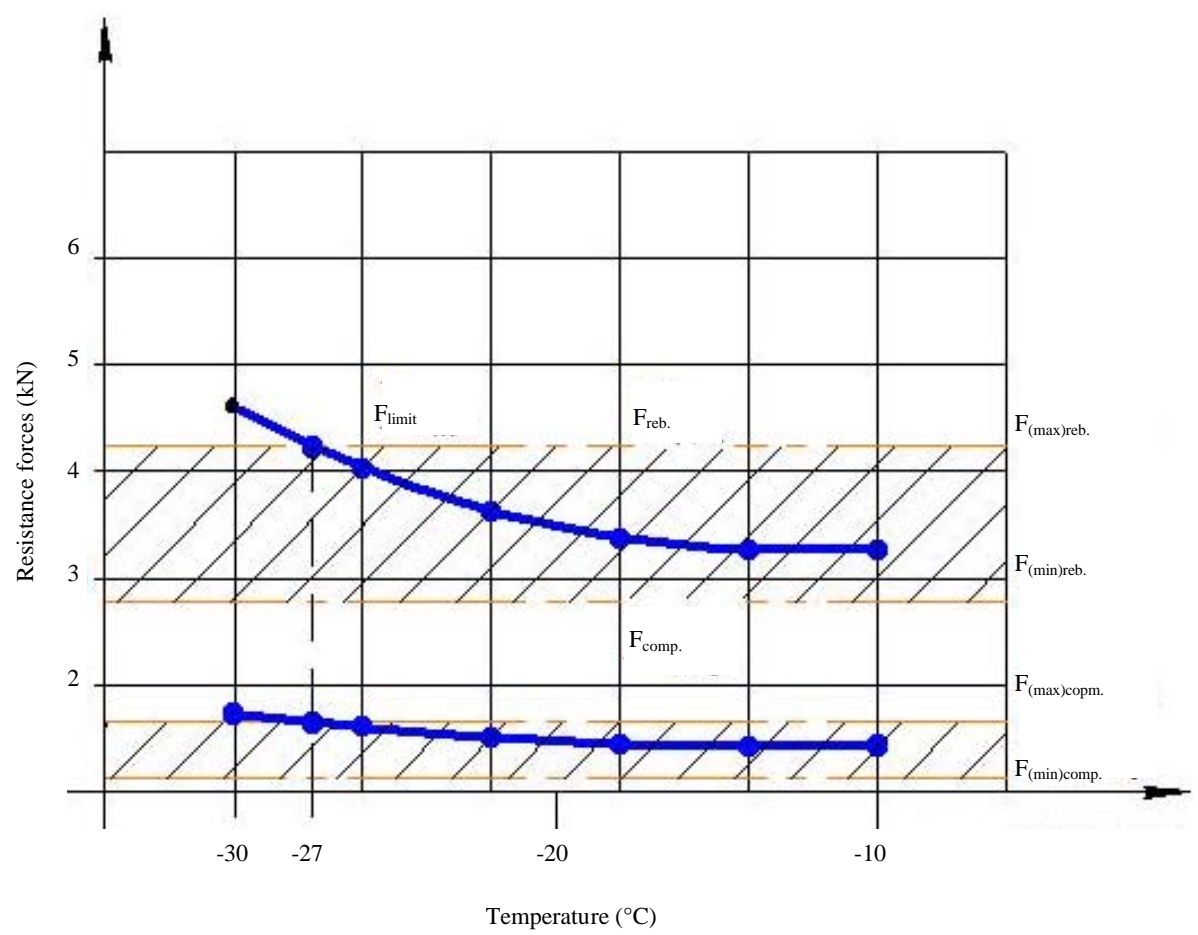

Fig. 1: Dynamic pattern of resistance forces of a hydraulic shock-absorber at subzero temperatures 


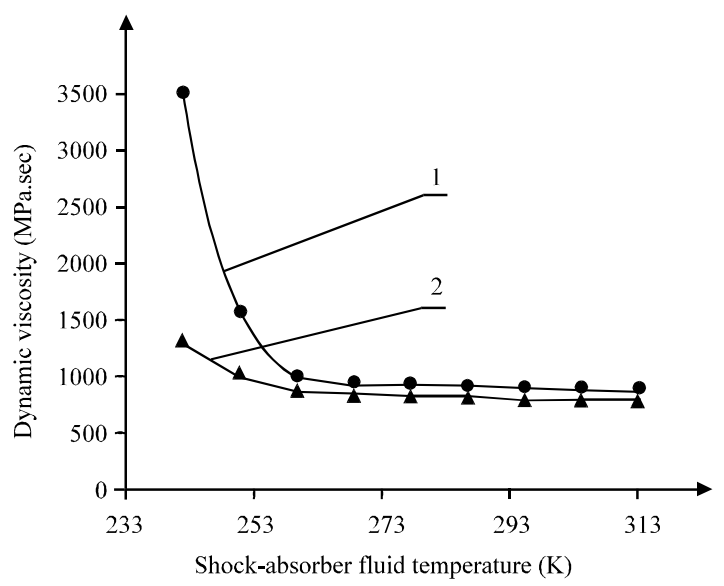

Fig. 2: Dynamic viscosity fluctuation of the shockabsorber fluid AZhl2-T (1) and the test fluid (2) depending on the temperature

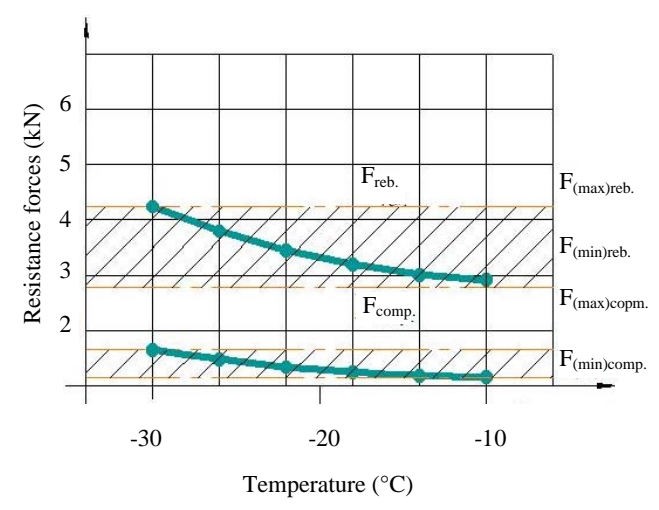

Fig. 3: Changes in shock-absorber resistance at rebound and compression when using the modified test shock-absorber fluid

Dynamic viscosity of the standard and test fluids are in a non-linear relationship with the temperatures in the range from $233-313 \mathrm{~K}$, further viscosity fluctuation is minor and does not go beyond $800 \mathrm{MPa}$.sec which is consistent with the requirements. Benchmark tests allow us to compare how resistance forces change when using the test fluid.

As proved by Fig. 3, resistance values at rebound and compression of shock-absorbers using the test fluid make it possible to use hydraulic shock-absorbers at subzero temperatures. Figure 3 illustrates how resistance forces change at rebound and compression when using the test fluid and the shock-absorber fluid AZhl2-T. A shaded area shows resistance values at rebound and compression in the subzero temperature range from $30^{\circ} \mathrm{C}$ below zero to $10^{\circ} \mathrm{C}$ below zero within which shock-absorbers are operable.

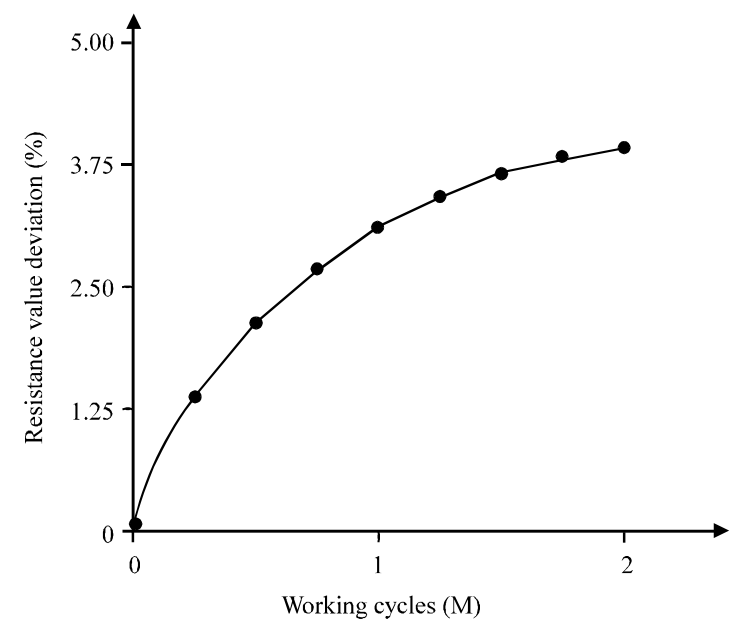

Fig. 4: Hydraulic shock-absorber life testing

To estimate the effect of the modified fluid on the component and node life, some wear tests on a special stand were performed (Domnyshev et al., 2016; Anonymous, 2012). The test mode corresponds to the operating mode of a hydraulic shock-absorber with the rod movement speed of $0.52 \mathrm{~m} / \mathrm{sec}$ and the amount of rod movement of $50 \mathrm{~m}$ at continuous operation with at least 2000000 cycles. In this mode resistance forces shall be stable and decrease shall not be more than $15 \%$. Test findings are represented by Fig. 4.

Diagram data analysis shows that resistance fluctuation does not exceed $4 \%$ when using the test fluid. Deviation in performance parameters never exceeds $15 \%$ which suggests practically no impact on shock-absorber component life.

\section{CONCLUSION}

We established that resistance forces of hydraulic shock-absorbers vary from $3230-4550 \mathrm{~N}$ at rebound with the max allowable value of $4022 \mathrm{~N}$ and from $830-1410 \mathrm{~N}$ at compression with the max allowable value of $1226 \mathrm{~N}$. Given values of resistance forces at rebound and compression are exceeded at the standard fluid temperature of $27^{\circ} \mathrm{C}$ below zero. To ensure performance, we suggest using the modified shock-absorber fluid with improved viscosity-temperature properties. This allows for almost a twofold decrease in dynamic viscosity of shock-absorber compared to the the use of standard fluid and helps to maintain performance of hydraulic shock-absorbers at subzero temperatures up to $30^{\circ} \mathrm{C}$ below zero. Life tests show that resistance fluctuation during 2, 000, 000 working cycles does not exceed 15\% when using the test fluid which suggests practically no impact on shock-absorber component life and possibilities of using this fluid in shock-absorbers of standard design. 


\section{REFERENCES}

Alekseevich, N.A., B.A. Valerevich, Z.D. Andreevich, S.P. Shcherbakov and G.A. Nikolaevich et al., 2016.

[Diagnostics of oil repair causes amortization stations of automobile transport]. Proceedings of the 6th International Conference on Youth Scientific Vol. 4, February 25-26, 2016, Kursk, Russia, pp: 185-188 (In Russian).

Anonymous, 2012. ST SEV 3044-81 GOST R 53816-2010: Vehicles Hydraulic telescopic shock absorbers; Technical requirements and test methods. Nami FGUP, Moscow, Russia.

Brusyantsev, N., N. Brusyantsev, G. Klinkovstein and G. Pokrovskiy, 1954. Study of Vehicle Operation at Various Viscosity and Temperatures of Oil in the Drivetrain Mechanism-Winter Operation of Vehicles: Collected works/Ministry of Motor Industry of the USSR, State All-Union Scientific and Research Institute of Motor Transport. Avtotransizdat, Moscow, Russia, Pages: 93.

Burdzik, R. and L. Konieczny, 2014. Vibration issues in passenger car. Transp. Prob., 9: 83-90.

Domnyshev, D., A. Dolgushin, D. Voronin, A. Kurnosov and D. Baranov, 2016. Feasibility of hydraulic shock-absorbers at subzero temperatures. Siberian J. Agric., 4: 79-85.
Gardulski, J. and J. Warczek, 2008. Investigation on forces in frictional kinematic pairs to assess their influence on shock absorber characteristics. Transp. Prob., 3: 19-24.

Gardulski, J., 2009. Diagnostic wear and tear of piston packing in car hydraulic shock absorbes. Transp. Prob., 4: 15-24.

Ishchenko, V. and Y. Shcherbina, 2017. Ways of improving the units construction of hydraulic shock absorbers of passenger cars on the bogie of kvz-cnii type. Metall. Min. Ind., 3: 24-31.

Izmaylov, A. and N. Yevtyushenko, 2013. Transportation services of the agri-industrial comples. Technol. Track- Laying Wheeled Veh., 5: 39-41.

Karasev, A., 2011. [Features of vehicles ride diagnostics on the example of technical condition of shock-absorbers used in agriculture (In Russian)]. Intl. Tech. Econ. J., 2: 140-143.

Konieczny, L., R. Burdzik and B. Sleziak, 2009. Usage of short time Fourier transform in identification of vehicle shock absorber technical conditions researched by force vibration method. Transp. Prob., 4: 71-77.

Ryabov, I., K. Chernyshov and S.M. Gasanov, 2014. [On safety of vehicles with defective shock-absorbers (In Russian)]. Land Transp. Syst., 9: 103-106.

Sobczak, P., 2009. Procedure of linear decimation in car suspension diagnosis. Transp. Prob., 4: 105-112. 